\title{
LOS ESTUDIOS SOBRE LA LENGUA DE LA PRIMERA CRÓNICA GENERAL (O ESTORIA DE ESPAÑA ALFONSÍ)
}

\begin{abstract}
Resumen. En el trabajo se pasa revista, mediante el análisis crítico de sus contenidos, a los estudios que desde los pioneros de Badía Margarit se han ocupado de determinados aspectos lingüísticos de la Estoria de España alfonsí. Los trabajos revisados, pese a su valía y a los hallazgos particulares, no han llegado, sin embargo, a constituir una línea de investigación sistemática y coherente.
\end{abstract}

Palabras clave: Estoria de España, lengua alfonsí, castellano medieval.

1. La Estoria de España alfonsí, rebautizada por Menéndez Pidal como Primera Crónica General, es un texto apasionante para los historiadores del español: con muy pocos antecedentes románicos, pero con una sólida tradición latina, no tiene parangón en su tiempo. El relato se construye sobre una compleja y variada gama de fuentes, latinas clásicas y medievales, árabes, romances, entrelazadas en adaptaciones y paráfrasis que los redactores, siguiendo el didactismo básico de la obra alfonsí, sometieron a una asombrosa labor de selección y ensamblado.

En la Estoria se cruzan discursos variados: relatos, diálogos, imprecaciones, evocaciones... que son las primeras elaboraciones lingüísticas en castellano escrito, en la distancia comunicativa, de tales actuaciones enunciativas. Construye así nuevas tradiciones discursivas en romance, apoyadas en las dadas por las lenguas de cultura del momento (el latín, también el árabe).

Pese a ello, no son muchos los estudios lingüísticos sobre la Estoria. Ha servido más como "documento" que como "monumento" para ejemplificar grafías y posibles sistemas fónicos, formas gramaticales y construcciones sintácticas, léxico... Con la Estoria se ha reflejado la evolución del castellano en la $2^{\mathrm{a}}$ mitad del XIII, a la vez que la "lengua alfonsí" en una de sus más notables muestras. Pero pocas veces ha sido analizada en sí misma, como texto señero.

\footnotetext{
* Universidad de Sevilla.
} 
2. Un primer conjunto de estudios sobre la lengua de la Estoria parte de su carácter de obra traducida del latín, o de versión de otro texto romance. En ese contraste de formas lingüísticas se intentan ver los rasgos constitutivos de su prosa.

2.1. Quizá los más conocidos y utilizados sean los trabajos de Badía Margarit (en especial 1959-1960 y 1960). En el primero Badía enfrenta fragmentos de las fuentes de la Estoria con sus versiones castellanas. El segundo, que aquí no se tendrá en cuenta (por utilizar la segunda parte, espuria, de la Estoria $\left.{ }^{1}\right)$, confronta el relato alfonsí del Cid con el Cantar; su título, «Dos tipos de lengua cara a cara», hizo fortuna en la lingüística hispánica posterior, y suministró las caracterizaciones tópicas con que se suele definir la sintaxis alfonsí (la "suelta", primitiva, anclada en la yuxtaposición, del Cantar, frente a la "trabada", más elaborada y cohesionada, pero con exceso de nexos y estos limitados, de la Estoria, todavía "primitiva").

Badía destaca de forma recurrente determinadas características, lo cual le sirve para resaltar la unidad fundamental de la Estoria, incluyendo primera y segunda parte, ratificando así el aserto de Menéndez Pidal: 'el borrador de toda la Crónica es obra de Alfonso X' (Badía, 1958-1959: $208)^{2}$. No obstante, señala que no siempre la traducción opera igual: hay fragmentos en los que la versión es fiel; en otros es más lejana, por lo que se sospecha la presencia de otras fuentes; y en otros el texto alfonsí resume, u omite, elementos de la fuente, por lo que la comparación se hace imposible (tales diversidades pueden darse dentro de un mismo fragmento ${ }^{3}$ ).

La primera de esas características es la ilación: los textos alfonsíes hacen explícita en mayor grado que los originales la vinculación entre los elementos componentes del texto, mediante elementos adverbiales y pronominales anafóricos, reiteración de la copulativa et, etc. A continuación, la preocupación por la subordinación: en el texto alfonsí la proporción de subordinadas es más elevada que en el original (aunque los originales puedan pertenecer a diferentes tradiciones discursivas y textuales). Este incremento de la subordinación lleva al ensanchamiento de la frase: aumenta el número de verbos, principales

${ }^{1}$ Aquí se utilizará solo el primer volumen de la Estoria publicada por Menéndez Pidal, pues, como ha quedado ampliamente demostrado, desde 1962, por Diego Catalán y sus discípulos (Inés Fernández-Ordóñez, Mariano de la Campa, etc.), es la única parte que se puede considerar salida verdaderamente del taller alfonsí.

2 Afirmación hoy difícilmente sostenible.

${ }^{3}$ Es el caso de la versión de la Farsalia de Lucano, el primer texto traducido estudiado por Badía. 
y subordinados; verbos y sustantivos simples del original quedan vertidos por dos elementos coordinados (pares cuasi sinonímicos); construcciones absolutas o de participio se traducen por secuencias oracionales, con o sin subordinación, etc. Con todo ello, aumenta el afán de precisión, vinculable al didactismo que permea toda la obra alfonsí: esa precisión puede llevar a la redundancia, que sin embargo formaba parte del modo en que los autores alfonsíes concebían su labor para con los destinatarios de su obra. Finalmente, Badía destaca que, de entre las subordinadas, dos son los tipos dominantes en la Estoria: las temporales, tanto por la naturaleza narrativa del discurso (a lo que Badía no alude) como por el carácter "primitivo" de estas; y las de relativo, a las que en contraste atribuye un origen culto, incluso de latinismo sintáctico, lo que parece injustificado, no solo porque las relativas constituyen en toda la historia del español el tipo de subordinación más abundante, sino porque, como señala Badía, pueden aparecer sin que estén en la fuente, por lo que difícilmente podrían atribuirse a imitación de la sintaxis latina.

Las dos primeras características señaladas por Badía se han utilizado por muchos autores como señales de lengua elaborada, alejada del primitivismo y de la proximidad a las realizaciones orales (lo habitual en los textos inaugurales de una lengua ${ }^{4}$ ). Pero justamente los textos latinos que se traducen se caracterizan por la falta de ilación interna, y ello no solo en un texto poético como la Farsalia, o de sintaxis tan particular (¿por su origen semítico?) como los Evangelios, sino también en textos narrativos como los Monumenta Germaniae Historica. Ahora bien, el mecanismo más habitual en la ilación alfonsí, la reiteración de et, podría considerarse, afirma Badía, una "fórmula primaria" de lo que en una sintaxis más elaborada serían oraciones subordinadas. De este modo, habría un contraste en la lengua alfonsí entre su utilización de subordinadas en mayor grado que el texto fuente $y$, en aparente contradicción, el recurso a secuencias paratácticas con valores de dependencia lógica. Hay otra contradicción no resuelta por Badía entre la menor presencia de subordinadas en los textos originales, lo que a veces califica de "simple" (p. ej., la Farsalia o los Monumenta), y su sustancial aumento en una lengua inicial, todavía "primitiva", aunque reducida, según Badía, a solo dos tipos. No parece advertir Badía que lo que se da entre latín y romance es una contraposición estructural de más hondo calado: el recurso en latín a las formas no personales para relaciones de dependencia, y el dominio de subordinadas con verbo en forma personal y nexo introductor en romance. Finalmente, otro hecho, destinado a mantener la cohesión textual, es la repetición de que tras

\footnotetext{
4 “Tono joven e inmaturo", según la metáfora tan habitual, son sus palabras.
} 
inciso, lo que llama, con falta de acierto, «rasgo del español primitivo» (Badía, 1958-1959: 198).

De la yuxtaposición no se habla en Badía 1958-1959, pues no existe en los textos alfonsíes analizados. Pero sí en Badía 1960: siguiendo la opinión más tradicional, la yuxtaposición, o sintaxis "suelta", es la forma propia de la transmisión oral, de las épocas primitivas de la lengua, del hablante inculto, del lenguaje infantil. De ahí su dominio en poemas épicos como el Cantar, dados el arcaísmo de su lenguaje y el «carácter oral de su divulgación y retransmisión» (Badía, 1960: 216). Pero aquí Badía oscila entre la hipótesis tradicional del primitivismo de la yuxtaposición y la visión de los dos tipos de lengua como dos "estilos", según ya intuyó Dámaso Alonso, a lo que finalmente parece adherirse, sin abdicar de verlos como dos fases en la elaboración de la lengua 5 . No tiene en cuenta, sin embargo, la consideración por Dámaso de "andadura rapidísima y modernísima" a propósito del Cantar por su conformación sintáctica. También Lázaro Carreter (1961), al confrontar un fragmento de la Estoria con su original latino (Suetonio), señaló cómo la sucesión yuxtapuesta de los complementos del original ("sintaxis sincopada, agilísima") no puede ser vertida fielmente por el texto alfonsí (habrá que esperar, dice, a Don Juan Manuel para andaduras de este tipo). No obstante, ese fragmento alfonsí es uno de los pocos en que la yuxtaposición oracional hace acto significativo de presencia, ya que, señala Lázaro, «al colaborador alfonsí le pareció, quizá, que era ésta la estructura más próxima a la veloz sucesión de complementos que figura en su modelo» (Lázaro, 1961: 104-105). Por tanto, aquíla yuxtaposición no tiene que ver con ninguna etapa "primitiva" de la elaboración sintáctica en la historia textual de una lengua, sino con la imitación de un modelo, latino, de máxima elaboración formal.

2.2. La historia de los trágicos amores de la reina Dido de Cartago y el troyano Eneas ha atraído la atención de los estudiosos por lo notable de su inclusión en la Estoria de España, dado que es un hecho tangencial a la historia romana de Hispania, y por el tratamiento lingüístico y estilístico, tan ligado a sus fuentes, en especial la Heroida VII de Ovidio ${ }^{6}$.

${ }^{5}$ La posición estilística de Dámaso Alonso puede hoy recuperarse en una perspectiva atenta a la dimensión textual y discursiva. La temporalista de Badía, común a buena parte de la Sintaxis histórica, se revela cada vez más como insostenible, al menos en la historia del castellano medieval.

${ }^{6}$ Para el tratamiento de las fuentes en este punto de la Estoria cfr. Impey, 1980: 1-6, 1982: 5-8 muestra cómo la labor lingüística de los redactores alfonsíes también se guiaba por objetivos estilísticos y estéticos, y cómo ello ha sido recibido por la moderna crítica filológica. 
Los estudios realizados sobre este fragmento, con atención muy particular a la carta enviada por la reina a Eneas, se han centrado en la amplificación por los redactores alfonsíes del texto de su fuente. Ello atañe más bien al contenido, pero parte del tratamiento lingüístico del texto. Impey (1980: 7 y sigs.) habla de amplificaciones "explicativas", donde se aclaran "costumbres, nombres, etc. desconocidos por la mayoría de los lectores / oyentes medievales», y que pueden ser tan inoportunas como aquella en que da cuenta, en definición enciclopédica, de quiénes eran las Euménides, o «endicheras dell ynfierno» (EE, 41b 34-37); amplificaciones "valorativas", con las que el redactor juzga la actuación de los personajes; y amplificaciones "retóricas", destinadas a crear un estilo elaborado con claras pretensiones estéticas, basado en las Retóricas de la época (como las "dualidades", sinonímicas o no, de la prosa alfonsí). El análisis de la función de esas amplificaciones las sitúa en el marco de la época y la ideología en que se mueve el texto al transformar el original ovidiano.

De muy distinto tipo es el cotejo realizado por esta autora entre el manuscrito regio de la primera parte de la Estoria (ms. E1) y los manuscritos de la versión vulgar que, en su opinión, representan un estado anterior de la redacción del texto, borradores previos de la versión "regia" (frente a la opinión habitual que los ve como copias posteriores). Los cambios, clasificados en adición, sustitución, omisión y de índole rítmica, «apuntan hacia un estilo más claro, coherente y elegante» (Impey, 1982: 17) ${ }^{7}$. Ahora bien, tanto en esta comparación (la versión "regia" frente a las "vulgares") como en la anterior (el texto alfonsí y sus fuentes latinas) apenas alude a procedimientos específicos de construcción sintáctica. Solo se utilizan, como muestra de ornato estilístico y uso retórico, los "sintagmas no progresivos", unión de elementos con diferentes grados de sinonimia.

También a propósito de la historia de Dido y Eneas, y en relación con Impey (1980), Ariza comparó las fuentes del episodio y la carta (Pompeyo Trogo, el Toledano, Ovidio) con la versión alfonsí. Si bien utilizó datos lingüísticos vinculados a la traducción (léxicos o gramaticales), tampoco entró en los modos de construcción sintáctica y se ciñó a observaciones críticas respecto a las conclusiones de Impey: no hay tanta amplificación en el relato alfonsí y la carta de Dido es muy fiel al original.

El breve análisis de Muñoz Garrigós (1985) sobre esta misma carta adoptó una actitud relativamentenovedosa, en cuanto quela "adversación" del título de su trabajo no se refiere tanto a los nexos así etiquetados, cuanto a la oposición establecida entre emisor (Dido) y receptor (Eneas),

${ }^{7}$ Nuevamente se revela que los autores alfonsíes tenían intenciones estéticas, formales, no solo didácticas y de contenido. 
relación dual que deriva en contraposición y que puede extenderse a otros personajes del texto. Este esquema opositivo, que puede manifestarse por el intercambio de funciones (sujeto vs. complemento) desempeñadas por los dos personajes centrales, es el armazón general del texto alfonsí.

Este relato y la carta de Dido constituyen una de las muestras más elaboradas de la prosa alfonsí, distinta a la habitual narración cronística, lo que refleja la complejidad y diversidad interna de esa prosa. En la carta se acumulan procedimientos sintáctico-discursivos variados: secuencias unidas por yuxtaposición (rara en la prosa alfonsí); conexión explícita, no solo con $e(t)$, sino, a veces combinados con él, casi todos los demás: el adversativo mas, en variasocasionesunidoaun pero todavía con valor de "sin embargo", el contrapositivo ante; el aditivo demas; los consecutivo-ilativos onde y por ende. Las hipótesis pueden introducirse por procedimientos que parecen derivar de los debates escolares: "E pongamos...", "Fagamos cuenta...". Prácticamente todos los tipos de subordinación están presentes, y si bien las relativas siguen dominando, las temporales tienen menor presencia, y cuando aparecen se entremezclan con valores de causa de enunciación. Las dualidades comparativas oracionales con assi $\operatorname{com}(m)$ $o$ son constantes. El conjunto de motivaciones cuya efectividad se niega lleva a concesivas con aunque, maguer (que), comoquier que, incluso el "primitivo" (?) que, concatenados entre sí muchas veces. La comparación con el poema ovidiano arroja resultados interesantes: casi ninguna de las subordinaciones del texto castellano tiene correspondencia en el latino, donde la yuxtaposición es dominante ${ }^{8}$.

2.3. Los posteriores análisis comparados de la Estoria con sus fuentes para buscar las raíces de la configuración sintáctica del discurso han sido escasos, sin generar una línea de estudios.

Cano Aguilar (1989) comparó el prólogo de la Estoria con su fuente directa, el de Rodrigo Ximénez de Rada en De rebus Hispaniae. Observa cómo determinados hechos del texto latino, propios de su sintaxis, no tienen acomodo en la versión alfonsí: así, el asíndeton del Toledano se convierte, entre otras, en secuencias con et reiterado. Así, la prosa alfonsí, en la tradición discursiva de los prólogos, adquiere una forma elaborada, "culta", pero no como los cultismos habituales, pues no se adopta sin más un elemento de la lengua de cultura.

En 2003 Rodríguez Toro confrontó nuevamente las fuentes latinas con sus versiones alfonsíes: frente a la habitual opinión de que la trabazón

${ }^{8}$ Utilizo dos ediciones de las Heroidas de Ovidio: la de Antonio Alatorre (México: UNAM, 1950: la Heroida VII ocupa las páginas 170-185, y los fragmentos en cuestión las páginas 176 y 180); y la de Lisa Piazzi, Heroidum Epistula VII Dido Aeneae (Firenze: Felice Le Monnier, 2007: 101 y 103). 
alfonsí no está tomada de las fuentes, en ocasiones sí responde a ello. Así, el uso de demostrativos como elementos de ilación; o la reiteración de et, ya habitual en los textos historiográficos medievales latinos. Finalmente, procedimientos de cohesión, con matices de sentido diferentes, ETIAM, VERO Y AUTEM, explican conectores como otrossi o el mismo et repetido, que sin embargo pierden al traducirlos esos matices.

3. Otros estudios se han centrado en la delimitación de las unidades supraoracionales y en los mecanismos sintácticos utilizados para ello.

A lo primero se dirige Elvira (1996-1997), quien intenta delimitar la unidad párrafo en la Estoria. Dada la dificultad de atribuir valor inequívoco, para pausas y entonación, a los signos de puntuación utilizados en el manuscrito, Elvira se concentró en los segmentos lingüísticos que delimitan esas secuencias enunciativas. Para ello tomó como criterio la presencia de sujetos, nominales o pronominales, explícitos, o su ausencia. En ello puede haber preferencias estilísticas o individuales; pero la presencia puede marcar la identidad del sujeto ( $p$. ej. con el enfatizador mismo), o deberse a la distancia textual con la primera mención, o a la contraposición entre sujetos de frases relacionadas, o a necesidades concretas de desambiguación referencial. Pero también la presencia de sujetos explícitos sirve a funciones demarcativas en la secuencia narrativa: rupturas en la continuidad de la narración; transiciones de un hilo principal a otro(s) secundario(s) (introducir comentarios del redactor-narrador, o informaciones o descripciones); recuperación del hilo narrativo; introducción de nuevas secuencias narrativas. Ese valor demarcador de párrafos otorgado al sujeto nominal puede venir reforzado por demostrativos o por el cambio de modos verbales.

González Cobas (2010 y 2012) parte de las unidades ya dadas en el manuscrito, los epígrafes y los capítulos que los componen, para señalar los elementos lingüísticos que concurren en esa segmentación textual. Así, los epígrafes suelen señalarse por medio de enunciados que contienen una referencia al mismo texto, con la explicitación del inicio de una secuencia de hechos. La estructura lingüística de los títulos de capítulos es igualmente repetitiva: un complemento "de asunto" con de, o una secuencia de relativo, o una suma de ambos. Los comienzos de los capítulos suelen consistir en una expresión temporal, a veces de extrema precisión, para lo que se emplean fórmulas diversas: construcciones absolutas o sintagmas preposicionales. También observa que la presencia de sujetos nominales explícitos constituye una función demarcadora, pues en general los capítulos comienzan con la presencia de ese nombre que inicia una nueva secuencia narrativa. Por otro lado, muchos capítulos muestran en su terminación "párrafos de transición", 
en que se anuncia el contenido del siguiente capítulo, o se retoma un hilo narrativo marginado por alguna información introducida en el decurso del relato. Dichos párrafos se inician con un mas de cambio de tópico, o un agora que establece contraste con lo anterior, algún verbo de "decir", y la referencia explícita al texto mismo. Finalmente, están los párrafos de "cierre", con acabar o dexar, o con referencias a hechos secundarios, que actúan como fórmulas de conclusión.

En cuanto a aspectos sintácticos de la Estoria, Roudil (1975) encuentra en el funcionamiento de $e$ tres posibilidades de orientación (bi-orientado a izquierda y derecha, solo a la derecha, o solo a la izquierda) en función de los elementos del discurso conectados por et. En Cano Aguilar (2002) se realizaron calas en la Estoria, junto con otros textos del XIII, con el doble objetivo de hallar pautas de construcción sintáctica del discurso y a partir de ahí confirmar, o no, la tradicional "teoría de la parataxis". En la Estoria se comprobó el dominio de las relaciones supraoracionales marcadas explícitamente, tanto en fragmentos narrativos como de otro tipo, si bien con escasa variedad de conectores. Esta situación se daba por igual en fragmentos narrativos y en la carta de Dido, pero en otros puntos hay diferencias relevantes: la yuxtaposición es siempre minoritaria, pero en la carta duplica su presencia frente al relato. La coordinación es superior en el relato que en la carta, al revés de lo que ocurre con "subordinadas" o "hipotácticas". En cuanto a los tipos de subordinación, si bien relativas y completivas son las más abundantes y constantes, en la narración hay mayor presencia de temporales, mientras que en la carta los siempre bajos porcentajes de condicionales y concesivas duplican a los del relato.

Por su naturaleza misma y por su tradición textual, no es la Estoria de España un texto propicio para hallar configuraciones sintácticas "orales", cercanas a la "inmediatez comunicativa" (pese a la consideración del et reiterado como marca de "oralismo"). Tampoco hay mímesis de diálogos, pues los pasajes en discurso directo suelen ser monólogos, en los que la sintaxis y la organización del discurso no difieren de las secuencias narrativas o descriptivas; solo el cambio de coordenadas deícticas en pronombres y verbos indica que el pasaje es responsabilidad de otro locutor. No obstante, pueden aparecer marcas indicadoras de la subjetividad del personaje enunciador (más allá del uso de pronombres personales y otros elementos deícticos), como subjuntivos que manifiesten lamentación o deseo. Otros signos de inscripción del sujeto enunciador en su discurso son la presencia de vocativos; interrogaciones "retóricas", preguntas con cómo que más bien manifiestan la extrañeza ante algo; uso de pongamos para introducir un supuesto (expresado en la completiva del verbo), seguido de una consecuencia lógica yuxtapuesta; 
presencia de determinadas formas de subordinación más propias de la interacción discursiva, como condicionales argumentativas, o polifónicas (eco y respuesta de enunciados anteriores); uso del pues inicial deenunciado y de respuesta y réplica. También se da en la Estoria un fenómeno habitual en el intercambio dialogal, la elipsis de elementos sintácticos presentes en una secuencia anterior. En el discurso dialogado dicho mecanismo se da entre los diferentes turnos que se van sucediendo. Evidentemente, la elipsis que solo deja en la respuesta un elemento constituye un claro procedimiento de focalización. Ya ha sido señalada también (Almeida, 2006) la frecuencia con que los redactores alfonsíes insertan discursos indirectos o directos donde no existen en las fuentes, sino en todo caso alusiones a actos de habla; o con que convierten discursos indirectos en directos.

\section{Bibliografía}

ALMEIDA, B. (2006). «La creación de discurso directo e indirecto en la historiografía alfonsí», en J. J. BUSTOS TOVAR y J. L. GIRÓN ALCONCHEL (eds.), Actas del VI Congreso Internacional de Historia de la Lengua Española, III. Madrid: Arco Libros / UCM / AHLE, 2639-2651.

ARIZA VIGUERA, M. (1997). «La Carta de Dido a Eneas. El proceso de traducción alfonsí», en Comentario lingüístico de textos (= Analecta Malacitana, anejo VIII) (M. CRESPILLO ed., P. CARRASCO comp.), 31-43.

BADÍA MARGARIT, A. M. (1958-1959). «La frase de la Primera Crónica General en relación con sus fuentes latinas (avance de un trabajo de conjunto)», Revista de Filología Española, XLII, 179-210.

BADÍA MARGARIT, A. M. (1960). «Dos tipos de lengua cara a cara», Studia Philologica. Homenaje a Dámaso Alonso, I. Madrid: Gredos, 115-139.

BADÍA MARGARIT, A. M. (1962). «Los "Monumenta Germaniae Historica” y la "Primera Crónica General" de Alfonso el Sabio», Strenae. Estudios de Filología e Historia dedicados al Profesor Manuel García Blanco. Salamanca: Universidad de Salamanca, 69-75.

CANO AGUILAR, R. (1989b). «Período oracional y construcción del texto en la prosa medieval castellana», Glosa, 1, 13-30.

CANO AGUILAR, R. (2002). «Sintaxis y discurso en la prosa del siglo XIII», en C. SARALEGUI y M. CASADO (eds.), Pulchre, bene, recte. Estudios en homenaje al Prof. Fernando González-Ollé. Pamplona: Ediciones Universidad de Navarra, S.A., 213-234.

CANO AGUILAR, R. (2012). «Diálogo y oralidad ficticia en las Crónicas medievales», en V. BÉGUELIN-ARGIMÓN, G. CARDONE y M. DE LA TORRE 
(eds.), En pos de la palabra viva: huellas de la oralidad en textos antiguos. Estudios en honor al profesor Rolf Eberenz. Berna: Peter Lang, 351-370.

ELVIRA, J. (1996-97). «La organización del párrafo alfonsí», Cahiers de Linguistique Hispanique Médiévale, 21 (De la variation linguistique et textuelle. En l'honneur de Jean Roudil. I. Linguistique médiévale). Paris: Éd. Klincsieck, 325-342.

GONZÁLEZ COBAS, J. (2008). "Construcciones anacolúticas en la Estoria de España de Alfonso X», en J. ELVIRA, I. FERNÁNDEZ-ORDÓÑEZ, J. GARCÍA GONZÁLEZ, A. SERRADILLA CASTAÑO (eds.), Lenguas, reinos y dialectos en la Edad Media ibérica. La construcción de la identidad. Homenaje a Juan Ramón Lodares. Frankfurt a.M.: Vervuert / Madrid: Iberoamericana, 321-339.

GONZÁLEZ COBAS, J. (2010). «Procedimientos de organización textual en la prosa alfonsí», Cahiers d'études hispaniques médiévales, 33, 197-213.

GONZÁLEZ COBAS, J. (2012). «Algunas técnicas de expresión narrativa en la Estoria de España de Alfonso X», en E. MONTERO CARTELLE (ed.), Actas del VIII Congreso Internacional de Historia de la Lengua Española, II. Meubook, 2193-2203.

IMPEY, O.-T. (1980). «Un dechado de la prosa literaria alfonsí: el relato cronístico de los amores de Dido», Romance Philology, XXXIV, 1, 1-27.

IMPEY, O.-T. (1982). «En el crisol de la prosa literaria de Alfonso X: unas huellas de preocupación estilística en las versiones del relato de Dido», Bulletin Hispanique, 84, 1-2, 5-23.

LÁZARO CARRETER, F. (1961). «Sobre el 'modus interpretandi' alfonsí», Ibérida. Revista de Filología, 6, 97-114.

MUÑOZ GARRIGÓS, J. (1985). «Un modelo de texto adversativo: 'La carta de Dido a Eneas' de la Primera Crónica General», en F. CARMONA y F. J. FLORES (eds.), La lengua y la literatura en tiempos de Alfonso X. Murcia: Universidad de Murcia, 365-372.

RODRÍGUEZ TORO, J. J. (2003). «Las estorias alfonsíes y dos de sus fuentes latinas cara a cara (datos para el estudio de la ilación)», Cahiers de linguistique et de civilisation hispaniques médiévales, 26, 241-257.

ROUDIL, J. (1975). «La 'Primera Crónica General' d'Alphonse le Savant: Structure du chapitre 688 et fonction de la copule 'et'», Revue de Linguistique Romane, 39, 381-393. 